Kong. Res. J. 1(2): 49-53, 2014

Kongunadu Arts and Science College, Coimbatore

\title{
SYNTHESIS AND CONFORMATIONAL STUDIES ON CERTAIN $N$-NITROSO PIPERIDIN-4-ONES
}

\author{
Ravindran, R.M ${ }^{*}$., and ${ }^{\mathrm{b}}$ S. S. Ilango \\ $a^{*}$ Department of Chemistry, Velammal institute of technology, Panchetti, Chennai. \\ ${ }^{\mathrm{b}}$ Department of Chemistry, Info Institute of Engineering, Coimbatore. \\ *E.mail: rmravindran08@gmail.com
}

\begin{abstract}
Heterocyclic compounds gain importance owing to their pharmacological, agro- hemical and in brief, biological activities. The piperidin-4-one units are present in a variety of alkaloids which are occurring naturally. They find wide applications as drugs. Further, the stereochemical studies of piperidinone chemistry are thought provoking and quiet interesting.
\end{abstract}

Keywords: $n$-nitroso piperidin-4-ones, Heterocyclic compounds, pharmacology.

\section{INTRODUCTION}

Piperidones are an important group of heterocyclic compounds in the field of medicinal chemistry due to their broad spectrum of biological activities. One such class of compounds containing 4piperidones and their derivatives, whose synthesis and stereodynamics are well investigated (Prostokov and Gaivoronskaya, 1978). Many natural products and drugs contain the piperidine ring system as a structural element. Nitrogen heterocycles, in particular 4-piperidones display important biological properties such as antiviral, antitumor, analgesics and antihypertensive activities (Miyoshi et al., 1995; Riley et al., 1973). The importance of 4piperidones as intermediates in the synthesis of a variety of compounds of physiological activity has been reviewed by Prostokov and Gaivoronskaya (Shintani et al., 2004). The extensive studies undertaken in the past on 4-piperidones have their relation to the synthesis of drugs (Boach et al., 1948)The utility of 2-aryl, 2-heteroarylpiperidin-4ones in the construction of polycyclic systems such as benzo[a]quinolin-4-ones, indole alkaloids, have been disclosed by Rubiralta et al., 1989 recently in a series of papers.

They have also described the importance of the introduction of bulky substituent in the nitrogen side of 4-piperidones, thereby making the ring system to adopt favorable conformation for the intramolecular ring closure leading to the construction of benzomorphon related compounds. Piperidone derivatives have also been noted to act as potential inhibitors of human placental aromatase in vitro. 3,5-bis(arylidine)piperidin-4-ones behave as cytotoxic and anticancer agents. 2,2,6,6tetramethylpiperidin-4-one hydrochloride has been used as a spin trap in several EPR studies and it's hydrazones are used as antioxidants. 2-Aryl piperidin-4-ones are used as key intermediates for the synthesis of techykinin antagonists and indolizidine alkaloids (Boach et al., 1948).

\section{EXPERIMENTAL SECTION}

Melting points of all the compounds were determined on an electrically heated block (RAAGA make) with a calibrated thermometer and are uncorrected. The IR spectra were recorded on a FTIR instrument (Perkin-Elmer). The ${ }^{1} \mathrm{H}$ NMR and ${ }^{13} \mathrm{C}$ NMR spectra were recorded on a Bruker AMX 400 $\mathrm{MHz}$ spectrometer and 2D NMR spectra were recorded on a AV $500 \mathrm{MHz}$ instrument in $\mathrm{CDCl}_{3}$ solution with TMS as an internal standard.

2.1. Synthesis of $r-2, c-6-B i s(2-c h l o r o p h e n y l)-c-3, t-3-$ dimethylpiperidin-4-one (1)

To a solution of ammonium acetate $(0.05$ mole) in dry ethanol, 2-Chlorobenzaldehyde (0.1 mole) and isopropylmethyl ketone (0.05 mole) was added. The above contents were taken in a round bottom flask and fitted with a double walled condensor. It was heated for 30 minutes. Then it was kept at room temperature overnight. The formed crystals of $r$-2,c-6-bis(2-chlorophenyl)-c-3,t-3dimethylpiperidin-4-one was filtered and washed well with the dry alcohol. Yield : $11.5 \mathrm{~g}$ (75\%) m.p: $148^{\circ} \mathrm{C}-150^{\circ} \mathrm{C} \& \mathrm{MS}(\mathrm{m} / \mathrm{z}): 347.31\left(\mathrm{M}^{+}\right), 276.14$, 252.06 (100\%), 149.22, 129.28, 115.18, 69.24

2.2. Synthesis of $r-2, c-6$-Bis(2-chlorophenyl)-t-3,t-5dimethylpiperidin-4-one (2)

To a solution of ammonium acetate $(0.05$ mole) in dry ethanol, 2-chlorobenzaldehyde $(0.1$ mole) and diethyl ketone $(0.05 \mathrm{~mole})$ was added. The above contents were taken in a round bottom flask and fitted with a double walled condensor. It was heated for 30 minutes. Then it was kept at room temperature overnight. The crystals of $r$-2,c-6-bis(2chlorophenyl)-t-3,t-5-dimethylpiperidin-4-one was separated was washed well with the dry alcohol. 
Yield : 12.51 g $(82 \%)$ m.p. : $117^{\circ} \mathrm{C}-120^{\circ} \mathrm{C}$ MS (m/z): 347.14( $\mathrm{M}^{+}$), 312.04, 252.08 (100\%), 152.21, 125.16, $117.25,73.19$

\subsection{Synthesis of $r$-2,c-6-Bis(2-chlorophenyl)-t-3- methylpiperidin-4-one (3)}

To a solution of ammonium acetate 0.05 mole) in dry ethanol 2-chlorobenzaldehyde (0.1 mole) and ethylmethyl ketone ( 0.05 mole) was added. The above contents were taken in a round bottom flask and fitted with a double walled condensor. It was heated for 30 minutes. Then it was kept at room temperature overnight. The crystals of r-2,c-6-bis(2-chlorophenyl)-t-3-methylpiperidin-4one was separated out was filtered and washed well with the dry alcohol. Yield : $7.6 \mathrm{~g}$ (53\%) m.p.: $124^{\circ} \mathrm{C}$ $126^{\circ} \mathrm{C}$

\section{RESULTS AND DISCUSSION}

In the present work, r-2,c-6-bis(2chlorophenyl)piperidin-4-ones $\quad \mathbf{1} \quad \boldsymbol{\&} \quad \mathbf{2}$ and their corresponding $N$-nitroso compounds $4 \quad \boldsymbol{4} \quad \mathbf{5}$ respectively, have been synthesized and their stereochemistry studied using IR spectra, ${ }^{1} \mathrm{H} \&{ }^{13} \mathrm{C}$ and $2 \mathrm{D}\left({ }^{1} \mathrm{H},{ }^{1} \mathrm{H}-\mathrm{COSY} \&{ }^{1} \mathrm{H},{ }^{13} \mathrm{C}\right.$-HETCOR $)$ NMR Spectra. The NMR spectral data reveal that all the parent piperidin-4-ones $\mathbf{1}$ \& $\mathbf{2}$ prefer chair conformation while the $N$-nitroso compounds $\mathbf{4} \& \mathbf{5}$ prefer to exist in a twist-boat conformation with coplanar orientation of $\mathrm{N}-\mathrm{N}=\mathrm{O}$ moiety.

3.1. $\quad r$-2, $c$-6-bis(2-chlorophenyl)c-3, t-3-dimethylpiperidin-4-one (1).

The piperidin-4-one $\mathbf{1}$ was synthesized by the reaction of isopropyl methyl ketone, 2chlorobenzaldehyde and ammonium acetate in ethanol medium at $100{ }^{\circ} \mathrm{C}$ (Scheme 11).

2<smiles>O=Cc1ccccc1Cl</smiles>

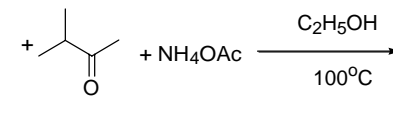

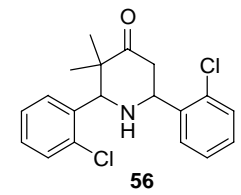

Scheme 1

The structure of the compound $\mathbf{1}$ was confirmed by IR spectra, ${ }^{1} \mathrm{H},{ }^{13} \mathrm{C}$ NMR, 2D NMR and mass spectral data.

The IR spectrum of piperidin-4-one $\mathbf{1}$, showed the presence of $>\mathrm{NH}$ (stretching band observed at $3306 \mathrm{~cm}^{-1}$ ) and $>\mathrm{C}=\mathrm{O}$ (stretching band observed at $1703 \mathrm{~cm}^{-1}$ ) groups, which confirmed the formation of the compound $\mathbf{1}$.

The ${ }^{1} \mathrm{H}$ NMR signals of the compound $\mathbf{1}$ were assigned by comparison with those of the corresponding 2,6-bis (2-clorophenyl) -3-methyl piperidin -4- one (3). The signal integration values were also used for the assignment.

The ${ }^{1} \mathrm{H}$ NMR spectrum of $\mathbf{1}$ has only $\mathrm{ABX}$ systems for the heterocyclic ring protons $\left(\mathrm{H}_{6 \mathrm{a}}, \mathrm{H}_{5 \mathrm{a}}\right.$ \& $\mathrm{H}_{5 \mathrm{e}}$ ) since no coupling partner is available at $\mathrm{C}_{3}$ for $\mathrm{C}_{2}$ proton, the benzylic proton at $\mathrm{C}_{2}$ appeared as a singlet at $3.79 \mathrm{ppm}$. The chemical shift value of $\mathrm{H}_{2}$ benzylic proton when compared to that of the 3 methyl analog $\mathbf{3}$ indicated the axial position for the proton and equatorial orientation for the chlorophenyl group. The signal at $4.59 \mathrm{ppm}$ with ${ }^{3} \mathrm{~J}$ values of $11.1\left({ }^{3} \mathrm{~J}_{6 \mathrm{a}}, 5 \mathrm{a}\right)$ and $5.1 \mathrm{~Hz}\left({ }^{3} \mathrm{~J}_{6 \mathrm{a}}, 5 \mathrm{e}\right)$, is assigned to the axial proton at $\mathrm{C}_{6}\left(\mathrm{H}_{6}\right)$ and it confirmed the equatorial orientation of the chlorophenyl group at $\mathrm{C}_{6}$. The coupling constant $\left({ }^{3} \mathrm{~J}_{6 \mathrm{a}, 5 \mathrm{a}} \&{ }^{3} \mathrm{~J}_{6 \mathrm{a}, 5 \mathrm{e}}\right)$ data were employed to calculate the dihedral angles between the vicinal protons $\left(\mathrm{H}_{6} \& \mathrm{H}_{5 \mathrm{a}}, \mathrm{H}_{5 \mathrm{e}}\right)$ by DAERM. The cis $\left(\mathrm{H}_{6}-\mathrm{C}_{6}-\mathrm{C}_{5}-\mathrm{H}_{5 \mathrm{e}}\right)$ and trans $\left(\mathrm{H}_{6}-\mathrm{C}_{6}-\mathrm{C}_{5}-\mathrm{H}_{5 \mathrm{a}}\right)$ dihedral angles of 1 were found to be $45^{\circ} \& 165^{\circ}$ respectively. The observed vicinal coupling constants and dihedral angles confirmed that the compound $\mathbf{1}$ prefer to exist in the chair conformation. The signal at $2.75 \mathrm{ppm}$ which appears as double doublet ( ${ }^{2} \mathrm{~J}_{5 \mathrm{a}}, 5 \mathrm{e}$ $=14.0 \mathrm{~Hz}$ and ${ }^{3} \mathrm{~J}_{6 \mathrm{a}, 5 \mathrm{a}}=12.0 \mathrm{~Hz}$ ) can be assigned to the axial proton of $\mathrm{C}_{5}\left(\mathrm{H}_{5 \mathrm{a}}\right)$. Similarly the signal at 2.66 ppm appeared as a double doublet with coupling constant values of $14.0 \mathrm{~Hz}\left({ }^{2} \mathrm{~J}_{5 \mathrm{a}}, 5 \mathrm{e}\right)$ and $3.5 \mathrm{~Hz}\left({ }^{3} \mathrm{~J}_{6 \mathrm{a}, 5 \mathrm{e}}\right)$ can be assigned to the equatorial proton at $\mathrm{C}_{5}\left(\mathrm{H}_{5 \mathrm{e}}\right)$.

The presence of $\mathrm{NH}$ proton at $1.75 \mathrm{ppm}$ was confirmed using the $\mathrm{D}_{2} \mathrm{O}$ exchange studies (Spectrum 3).

The ${ }^{13} \mathrm{C}$ NMR spectrum signals (Spectrum 4) of the Compound $\mathbf{1}$ were assigned on the basis of additivity and by comparison with those of the corresponding 2,6-bis (2-clorophenyl) -3-methyl piperidin -4- one( 3 ).

On the basis of the above discussion, it has been concluded that $r$-2,c-6-bis (2-chlorophenyl) $-c-3, t-3$ dimethylpiperidin-4-one (1) prefers to adopt a chair conformation with the equatorial orientation of chlorophenyl groups at $\mathrm{C}_{2}$ and $\mathrm{C}_{6}$ positions (Fig. 1).

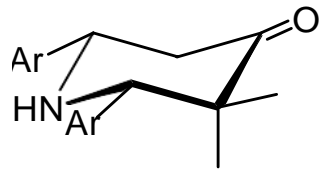

Fig. 1

The complete assignments of ${ }^{1} \mathrm{H}$ and ${ }^{13} \mathrm{C}$ NMR spectral data are presented in Table $1 \& \mathbf{2}$.

The piperidin-4-one $\mathbf{2}$ was synthesized by the reaction of pentan-3-one, 2-chlorobenzaldehyde and ammonium acetate in ethanol medium at $100{ }^{\circ} \mathrm{C}$ (Scheme 2). 


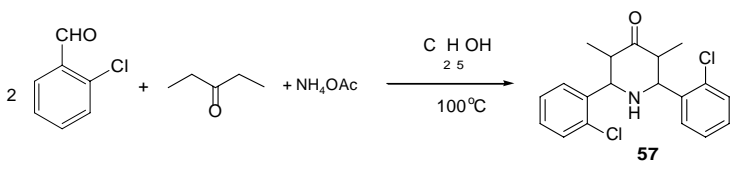

Scheme 2

The structure of the compound was confirmed by IR spectra, ${ }^{1} \mathrm{H},{ }^{13} \mathrm{C}$ NMR, 2D NMR and mass spectral data.

The presence of $\mathrm{NH}$ stretching band (3310 $\left.\mathrm{cm}^{-1}\right)$ and $>\mathrm{C}=0$ stretching band $\left(1704 \mathrm{~cm}^{-1}\right)$ in the IR spectrum of the compound 2 indicated the formation of the compound 2 .

The compound $\mathbf{5 7}$ is symmetrical in nature and the assignment of ${ }^{1} \mathrm{H}$ NMR chemical shifts is very simple. The protons at $\mathrm{C}_{2}$ and $\mathrm{C}_{6}$ are chemically equivalent. Similarly the protons at $\mathrm{C}_{3}$ and $\mathrm{C}_{5}$ are also equivalent. Hence the ${ }^{1} \mathrm{H}$ NMR spectrum of 2 has only AX spin system for the heterocyclic ring protons.

The benzylic protons $\left(\mathrm{H}_{2 \mathrm{a}}\right.$ and $\left.\mathrm{H}_{6 \mathrm{a}}\right)$ showed a doublet at 4.38 ppm with ${ }^{3} \mathrm{~J}_{2 \mathrm{a}, 3 \mathrm{a}}\left(={ }^{3} \mathrm{~J}_{6 \mathrm{a}}, 5 \mathrm{a}\right)$ value of $10.3 \mathrm{~Hz}$, indicating that these two protons are diaxially oriented which in turn confirm the equatorial orientation of chlorophenyl groups at $\mathrm{C}_{2}$ $\& \mathrm{C}_{6}$ and methyl groups at $\mathrm{C}_{3} \& \mathrm{C}_{5}$ respectively. The diaxial coupling constant of $10.3 \mathrm{~Hz}$ confirms the preference of chair conformation for the compound 2.

On the basis of the above observations, it has been concluded that $r$-2,c-6-bis (2chlorophenyl)-t-3,t-5-dimethylpiperidin-4-one (2), exist in chair conformation with the equatorial orientation of chlorophenyl substituent of $\mathrm{C}_{2}$ and $\mathrm{C}_{6}$ and methyl groups at $\mathrm{C}_{3}$ and $\mathrm{C}_{5}$ respectively similar to the previous compound.

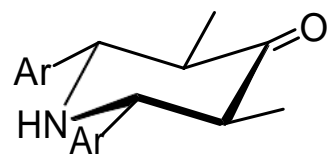

Fig. 2

The complete assignments of ${ }^{1} \mathrm{H}$ and ${ }^{13} \mathrm{C}$ NMR spectral data are presented in the Table 3 and 4.

3.2. $r$-2,c-6-Bis(2-chlorophenyl)-t-3-methylpiperidin-4one (3)

The titled compound was synthesized by the reaction of butan-2-one,2-chlorobenzaldehyde and ammonium acetate in ethanol medium at $100{ }^{\circ} \mathrm{C}$ (Scheme 3).

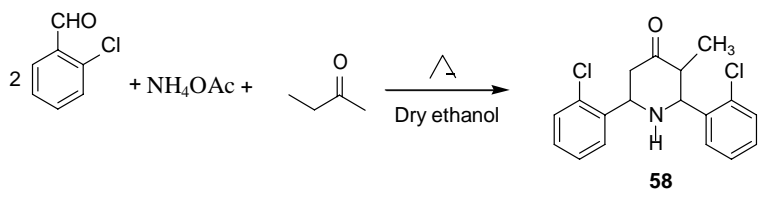

Scheme 3

The structure of the compound was confirmed by IR spectra, ${ }^{1} \mathrm{H} \&{ }^{13} \mathrm{C}$ NMR spectral data. In addition DEPT spectrum was also used for the assignment of ${ }^{13} \mathrm{C}$ NMR spectrum.

The ${ }^{1} \mathrm{H}$ NMR spectrum of $\mathbf{3}$ has $\mathrm{ABX}$ and $\mathrm{AX}$ spin systems for the heterocyclic ring protons. The $\mathrm{H}_{6 \mathrm{a}}, \mathrm{H}_{5 \mathrm{a}}$ and $\mathrm{H}_{5 \mathrm{e}}$ protons which belongs to the $\mathrm{ABX}$ spin system and the $\mathrm{H}_{6 \mathrm{a}}$ and $\mathrm{H}_{5 \mathrm{e}}$ protons (AX spin system) showed two double doublets at 4.07 and $2.62 \mathrm{ppm}$ respectively, were assigned on the basis of the magnitudes of their coupling constant (J) values. The $\mathrm{H}_{5 \mathrm{a}}$ of the $\mathrm{ABX}$ spin system was found to have been mingled with the $\mathrm{H}_{3 \mathrm{a}}$ (multiplet) of the AX spin system. The signal at $4.07 \mathrm{ppm}$ with ${ }^{3} \mathrm{~J}$ values of 11.5 and $3.5 \mathrm{~Hz}$, ascribable to ${ }^{3} \mathrm{~J}_{6 a, 5 a}$ and ${ }^{3} \mathrm{~J}_{6 a, 5 \mathrm{e}}$, respectively, was assigned to the axial proton at $\mathrm{C}_{6}$ $\left(\mathrm{H}_{6}\right)$ which confirmed the equatorial orientation of the chlorophenyl group at $\mathrm{C}_{6}$. The signal at $2.62 \mathrm{ppm}$, can also be assigned to the equatorial proton at $\mathrm{C}_{5}$ $\left(\mathrm{H}_{5} \mathrm{e}\right)$. Similarly, the proton $\mathrm{H}_{2}$ of the AX spin system gave a doublet at $3.61 \mathrm{ppm}$ with a ${ }^{3} \mathrm{~J}_{2 \mathrm{a}, 3 \mathrm{a}}$ value of $10.5 \mathrm{~Hz}$, indicating that these two protons are diaxially oriented, which in turn confirmed the equatorial orientation of the chlorophenyl and methyl groups at $\mathrm{C}_{2}$ and $\mathrm{C}_{3}$, respectively. Due to the coupling with $\mathrm{CH}_{3}$ protons, the $\mathrm{H}_{3 a}$ proton appeared as a multiplet at $2.62 \mathrm{ppm}$. The coupling constant $\left(3_{6,5 a} \&{ }^{3} J_{6,5}\right)$ data were employed to calculate the dihedral angles between the vicinal protons $\left(\mathrm{H}_{6}\right.$ \& $\left.\mathrm{H}_{5 \mathrm{a}}, \mathrm{H}_{5 \mathrm{e}}\right)$ by DAERM. ${ }^{74}$ The cis $\left(\mathrm{H}_{6}-\mathrm{C}_{6}-\mathrm{C}_{5}-\mathrm{H}_{5 \mathrm{e}}\right)$ and trans $\left(\mathrm{H}_{6}-\mathrm{C}_{6}-\mathrm{C}_{5}-\mathrm{H}_{5 \mathrm{a}}\right)$ dihedral angles of 3 were found to be $\mathbf{5 4}^{\circ}$ and $\mathbf{1 7 4}^{\circ}$, respectively. The observed vicinal coupling constants and dihedral angles are consistent with the chair conformation for $\mathbf{3}$.

On the basis of the above discussion, it was concluded that $r$-2,c-6-bis(2-chlorophenyl)- $t$-3methylpiperidin-4-one (3), similar to other 2,6diphenyl piperidin-4-ones, prefers to adopt a chair conformation with the equatorial orientation of chlorophenyl substituents at $\mathrm{C}_{2} \& \mathrm{C}_{6}$ and methyl group at $\mathrm{C}_{3}$ respectively(Fig. 3 ).

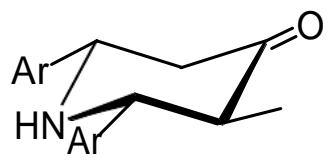

Fig. 3

The complete assignment of ${ }^{1} \mathrm{H} \&{ }^{13} \mathrm{C}$ NMR data are presented in the Table $5 \mathbf{\&} 6$. 


\section{SUMMARY}

Three piperidin-4-ones viz. $r$-2,c-6-bis(2chlorophenyl)-c-3,t-3-dimethylpiperidin-4-one $r$-2,c-6-bis(2-chlorophenyl)- $t$-3,t-5-

dimethylpiperidin-4-one (2) and $r$-2,c-6-bis (2-

chlorophenyl)-t-3-methylpiperidin-4-one (3) have been synthesized.

The preferred conformations of these

compounds 1-3 have been determined using IR spectra, ${ }^{1} \mathrm{H},{ }^{13} \mathrm{C}$, DEPT and $2 \mathrm{D}\left({ }^{1} \mathrm{H},{ }^{1} \mathrm{H}-\mathrm{COSY} \&{ }^{1} \mathrm{H},{ }^{13} \mathrm{C}\right.$ HETCOR) NMR spectra. The NMR data indicated that the parent piperidin-4-ones 56-58 adopt chair conformation.

\section{REFERENCES}

Boach, J., M. Rubiralta, M. Moral and J. Bolos (1948). Benzomorphan-related compounds. Part 21. Synthesis of 7, 8-benzomorphans via 2-aryl-4piperidones. J Chem Soc, Perkin Trans 1: 14591465.

Miyoshi, N., V. Mishik, M. Fukuda and P. Riesz, (1995). Effect of gallium-porphyrin analogue ATX-70 on nitroxide formation from a cyclic secondary amine by ultrasound: on the mechanism of sonodynamic activation. Radiat Res 143: 194-200.

Riley, T.N, D.B. Hale and N.C. Wilson, (1973). 4-anilidopiperidine analgesics I: Synthesis and analgesic activity of certain ring-methylated 1-substituted 4-propananilidopiperidines. J Pharm Sci 62 : 983-990.

Rubiralta, M and M.P. Marco, (1989). Synthetic applications of 2-aryl-4-piperidones. V1.: Synthesis of the fundamental tetracyclic skeleton of ervitsine and its 20-deethylidene-6, 16-dihydro analogue. Hetrocycles 29 : 2185 2191.

Shintani, R., N. Tokunaga, H. Doi and T. Hayashi, (2004). A new entry of nucleophiles in rhodium-catalyzed asymmetric 1, 4-addition reactions: Addition of organozinc reagents for the synthesis of 2-aryl-4-piperidones. $J \mathrm{Am}$ Chem $S 126$ : 6240-6248.
Table 1. Assignment of ${ }^{1} \mathrm{H}$ NMR Spectrum of $r$ 2,c- 6- bis (2-chlorophenyl) -c-3, $t$-3 -dimethyl piperidin-

\begin{tabular}{|c|c|c|c|}
\hline No & $\begin{array}{c}\text { Chemical Shift }(\delta \\
\text { ppm) }\end{array}$ & Assignment & $\begin{array}{c}\text { Coupling } \\
\text { Constant } \\
(\mathrm{Hz})\end{array}$ \\
\hline 1 & $\begin{array}{l}7.39-7.20(\mathrm{~m}, \\
8 \mathrm{H})\end{array}$ & $\begin{array}{l}\text { Aromatic } \\
\text { protons }\end{array}$ & \\
\hline 2 & $4.59(\mathrm{dd}, 1 \mathrm{H})$ & $\mathrm{H}_{6 \mathrm{a}}$ & $\begin{array}{l}J_{5 a, 6 a}=11.1 \\
J_{5 e, 6 a}=5.1\end{array}$ \\
\hline 3 & $3.79(\mathrm{~s}, 1 \mathrm{H})$ & $\mathrm{H}_{2 \mathrm{a}}$ & \\
\hline 4 & $2.75(\mathrm{dd}, 1 \mathrm{H})$ & $\mathrm{H}_{5 \mathrm{a}}$ & $\begin{array}{l}J_{5 a, 5 e}=14 \\
J_{5 a, 6 a}=12\end{array}$ \\
\hline 5 & $2.66(\mathrm{dd}, 1 \mathrm{H})$ & $\mathrm{H}_{5 \mathrm{e}}$ & $\begin{array}{l}\mathrm{J}_{5 \mathrm{a}, 5 \mathrm{e}}=14 \\
\mathrm{~J}_{5 \mathrm{e}, 6 \mathrm{a}}=3.5\end{array}$ \\
\hline 6 & $\begin{array}{l}1.75^{*} \\
\text { exchangeable } \\
\left.\text { with } \mathrm{D}_{2} \mathrm{O}\right)\end{array}$ & $\mathrm{NH}$ & \\
\hline 7 & $1.26(\mathrm{~s}, 3 \mathrm{H})$ & $\mathrm{CH}_{3}$ at $\mathrm{C}_{3}$ & \\
\hline 8 & $1.02(\mathrm{~s}, 3 \mathrm{H})$ & $\mathrm{CH}_{3}$ at $\mathrm{C}_{3}$ & \\
\hline
\end{tabular}

* Extracted from ${ }^{1} \mathrm{H}$ NMR $\left(\mathrm{D}_{2} \mathrm{O}\right.$ exchanged $)$ Spectrum

Table 2. Assignment of ${ }^{13} \mathrm{C}$ NMR spectrum of $r$ -

\begin{tabular}{|c|c|c|}
\hline $\begin{array}{c}\text { S. } \\
\text { No }\end{array}$ & Chemical Shift ( $\delta$ ppm) & Assignment \\
\hline 1 & 211.74 & $\mathrm{C}_{4}>=0$ \\
\hline 2 & $\begin{array}{ll}140.2, & 136.9, \\
134.2,132.5 & \end{array}$ & $\begin{array}{l}\text { Aromatic } \quad \text { (ipso) } \\
\text { Carbons }\end{array}$ \\
\hline 3 & $\begin{array}{l}130.5, \quad 129.6, \quad 128.7 \\
128.6,127.4,126.3\end{array}$ & Aromatic Carbons \\
\hline 4 & 63.03 & $\mathrm{C}_{2}$ \\
\hline 5 & 57.09 & $\mathrm{C}_{6}$ \\
\hline 6 & 50.85 & $\mathrm{C}_{3}$ \\
\hline 7 & 44.68 & $\mathrm{C}_{5}$ \\
\hline 8 & 20.45 & $\mathrm{CH}_{3}$ at $\mathrm{C}_{3}$ \\
\hline 9 & 20.02 & $\mathrm{CH}_{3}$ at $\mathrm{C}_{3}$ \\
\hline
\end{tabular}


Table 3. Assignment of ${ }^{1} \mathrm{H}$ NMR Spectrum of $\boldsymbol{r}$ 2,c-6-bis(2-chlorophenyl) $t$-3,t-5-dimethylpiperidin-4-one (2)

\begin{tabular}{|c|c|c|c|}
\hline Si. & $\begin{array}{c}\text { Chemical Shift } \\
(\delta \mathrm{ppm})\end{array}$ & Assignment & $\begin{array}{c}\text { Coupling } \\
\text { Constant } \\
(\mathrm{Hz}) \\
\end{array}$ \\
\hline 1 & $\begin{array}{l}7.35-7.19(\mathrm{~m}, \\
8 \mathrm{H})\end{array}$ & $\begin{array}{l}\text { Aromatic } \\
\text { protons }\end{array}$ & $\mathrm{J}_{2 \mathrm{a}, 3 \mathrm{a}}=\mathrm{J}_{5 \mathrm{a}, 6 \mathrm{a}}$ \\
\hline 2 & $4.38(\mathrm{~d}, 2 \mathrm{H})$ & $\mathrm{H}_{2 \mathrm{a}} \& \mathrm{H}_{6 \mathrm{a}}$ & $=10.3$ \\
\hline 3 & $2.79(\mathrm{bs}, 2 \mathrm{H})$ & $\mathrm{H}_{3 \mathrm{a}} \& \mathrm{H}_{5 \mathrm{a}}$ & \\
\hline 4 & $\begin{array}{l}1.75(\mathrm{bs}, \\
\text { exchangeable } \\
\left.\text { with } \mathrm{D}_{2} \mathrm{O}\right)\end{array}$ & $-\mathrm{NH}$ & \\
\hline 5 & $0.92(\mathrm{~d}, 6 \mathrm{H})$ & $\begin{array}{l}-\mathrm{CH} \text { at } \mathrm{C}_{3} \& \\
\mathrm{C}_{5}\end{array}$ & $J=6.5$ \\
\hline
\end{tabular}

Table 4. Assignment of ${ }^{13} \mathrm{C}$ NMR Spectrum of $r$ 2,c-6-bis(2-chlorophenyl) dimethylpiperidin-4-one (2)

\begin{tabular}{cll}
\hline $\begin{array}{c}\text { S. } \\
\text { No }\end{array}$ & \multicolumn{1}{c}{$\begin{array}{c}\text { Chemical Shift }(\delta \\
\text { ppm })\end{array}$} & \multicolumn{1}{c}{ Assignment } \\
\hline 1 & 210.14 & $\mathrm{C}_{4}>=0$ \\
& & $\begin{array}{l}\text { Aromatic } \\
\text { Carbons }\end{array}$ \\
2 & $139.1,133.9$ & Aromatic Carbons \\
3 & $129.4,128.7,127.3$ & $\mathrm{C}_{2} \& \mathrm{C}_{6}$ \\
4 & 62.49 & $\mathrm{C}_{3} \& \mathrm{C}_{5}$ \\
5 & 51.98 & $\mathrm{CH}_{3}$ at $\mathrm{C}_{3} \& \mathrm{C}_{5}$ \\
6 & 9.93 & \\
\hline
\end{tabular}

Table 5. Assignment of ${ }^{1} \mathrm{H}$ NMR spectrum of $r$ - $2 c$ 6-bis(2-chlorophenyl)- $t$-3- ethylpiperidin-4-one (3)

S. Chemical shift Coupling
No $\quad \begin{aligned} & \text { Shemical shift } \\ & \text { Nopm })\end{aligned}$ Assignment constant $(\mathrm{Hz})$

$1 \quad 7.46$ to $7.26(8 \mathrm{H}) \quad$ Aromatic

protons

$24.07(\mathrm{dd}, 1 \mathrm{H}) \quad \mathrm{H}_{6 \mathrm{a}} \quad \mathrm{J}_{5 \mathrm{a}, 6 \mathrm{a}}=11.5$

$\mathrm{J}_{5 \mathrm{e}, 6 \mathrm{a}}=3.5$

$3 \quad 3.61(\mathrm{~d}, 1 \mathrm{H}) \quad \mathrm{H}_{2 \mathrm{a}} \quad \mathrm{J}_{2 \mathrm{a}, 3 \mathrm{a}}=10.5$

$4 \quad 2.62(\mathrm{~m}, 3 \mathrm{H}) \quad \mathrm{H}_{3 \mathrm{a}} \& \mathrm{H}_{5 \mathrm{a}, 5 \mathrm{e}}$

5 exchangeable $^{(\mathrm{s},} \mathrm{NH}$ with $\mathrm{D}_{2} \mathrm{O}$ )

$6 \quad 0.83(\mathrm{~d}, 3 \mathrm{H}) \quad \mathrm{CH}_{3}$ at $\mathrm{C}_{3} \quad \mathrm{~J}=6.5$

*Extracted from ${ }^{1} \mathrm{H}$ NMR $\left(\mathrm{D}_{2} \mathrm{O}\right.$ exchanged $)$ spectrum.

Table 6. Assignment of ${ }^{13} \mathrm{C}$ NMR spectrum of $r$-2,c6-bis(2-chlorophenyl)- $t$-3-methylpiperidin-4one (3)

\begin{tabular}{lll}
\hline S. No & \multicolumn{1}{c}{$\begin{array}{c}\text { Chemical shift } \\
(\delta \mathrm{ppm})\end{array}$} & \multicolumn{1}{c}{ Assignment } \\
\hline 1 & 208.61 & $\mathrm{C}_{4}>=0$ \\
2 & $141.08,140.22,133.60$, & $\begin{array}{l}\text { Aromatic } \quad \text { (ipso) } \\
\text { carbons }\end{array}$ \\
& $133.02 \quad 129.0,128.9$, & Aromatic carbons \\
3 & $131.5,127.8$ & $-\mathrm{C}_{2}$ \\
4 & $128.8,12.69$ & $-\mathrm{C}_{6}$ \\
5 & 60.89 & $-\mathrm{C}_{3}$ \\
6 & 51.63 & $-\mathrm{C}_{5}$ \\
7 & $50.81^{*}$ & $-\mathrm{CH}_{3}$ at $\mathrm{C}_{3}$ \\
8 & 10.06 & \\
\hline
\end{tabular}

*Extracted from DEPT spectrum. 